\title{
Elastic composite skin for a pure shear morphing wing structures
}

DOI:

10.1177/1045389X14526796

Link to publication record in Manchester Research Explorer

\section{Citation for published version (APA):}

Wu, R., Sun, J., Chang, Z., Bai, R., \& Leng, J. (2014). Elastic composite skin for a pure shear morphing wing structures. 352-363. https://doi.org/10.1177/1045389X14526796

\section{Citing this paper}

Please note that where the full-text provided on Manchester Research Explorer is the Author Accepted Manuscript or Proof version this may differ from the final Published version. If citing, it is advised that you check and use the publisher's definitive version.

\section{General rights}

Copyright and moral rights for the publications made accessible in the Research Explorer are retained by the authors and/or other copyright owners and it is a condition of accessing publications that users recognise and abide by the legal requirements associated with these rights.

\section{Takedown policy}

If you believe that this document breaches copyright please refer to the University of Manchester's Takedown Procedures [http://man.ac.uk/04Y6Bo] or contact uml.scholarlycommunications@manchester.ac.uk providing relevant details, so we can investigate your claim.

\section{OPEN ACCESS}




\title{
Elastic composite skin for a pure shear morphing wing structures
}

Journal of Intelligent Material System and Structures 20I5, Vol. 26(3) 352-363 (C) The Author(s) 2014 Reprints and permissions: sagepub.co.uk/journalsPermissions.nav DOI: 10.1 I77/I045389X|4526796 jim.sagepub.com (SAGE

\author{
Rui Wu', Jian Sun ${ }^{2}$, Zhizhong Chang ${ }^{3}$, Rui Bai ${ }^{3}$ and Jinsong Leng ${ }^{2}$
}

\begin{abstract}
This study is focused on developing a morphing skin that can perform $\pm 30^{\circ}$ pure shear morphing. Carbon fibrereinforced plastic rods-reinforced and Kevlar-reinforced silicone rubber matrix composite skin is designed, fabricated, tested, and utilized on the demonstrator wing. This skin design has achieved satisfactory wrinkle onset angle $\left(>50^{\circ}\right)$ without applying pre-tension or pre-stretch, low in-plane shear stiffness that allows the skin of $\mathrm{I} \mathrm{m} \mathrm{m}^{2}$ to perform $30^{\circ}$ shear morphing under $30 \mathrm{~kg}$ actuating force, designable out-of-plane stiffness, considerable damage tolerance, and simplicity in fabrication. This article describes the designing process of the skin, where a carbon fiber-reinforced plastic rodreinforced skin is tested and revised to the final design; the study on the mechanism of different types of wrinkles as well as the strategies of wrinkles reduction, where two complementary wrinkle characterization methods are used; analysis and testing on out-of-plane stiffness; and finally, the utilization of skin on a demonstrator morphing wing structure. The presented skin can also be used as morphing face sheet.
\end{abstract}

\section{Keywords}

Morphing skin, morphing aircraft, morphing wing, composite skin, shear morphing, wrinkle reduction, wrinkle characterization

\section{Introduction}

Aircraft morphing, which means changing the shape of aircraft during flight according to the required performance, can increase the aircraft's efficiency and versatility that is of importance in commercial and military aviation (Barbarino et al., 2011; Love et al., 2007; Rodriguez, 2007). The development of morphing aircraft has arose the demand for morphing skin that can form a smooth aerodynamic surface and transmit aerodynamic pressure to the supporting structures while performing continuous deformation (Airoldi et al., 2012; Murugan et al., 2012; Thill et al., 2008).

The design of skin is challenging because it should achieve high loading capacity (high out-of-plane stiffness) while maintaining low actuating work (low inplane stiffness) (Bubert et al., 2010; Joo et al., 2009). In order to meet the demand for morphing skins, studies have been carried out: corrugated structure can be used for one-dimensional (1D) morphing since its orthotropic stiffness properties allow it to carry load in one direction while remaining deformable in another (Dayyani et al., 2013; Thill et al., 2010; Yokozeki et al., 2006); unidirectional fiber-reinforced elastic skin can achieve considerable load-bearing capacity when pretension is applied along the fiber direction (Chen et al., 2013; Murray et al., 2010); elastic face sheet supported by honeycomb substructure is capable of shear morphing, extensional morphing, and 1D morphing (Bubert et al., 2010; Chen et al., 2013; Olympio et al., 2010; Olympio and Gandhi, 2007, 2010; Scarpa and Tomlin, 2000; Vos and Barrett, 2010, 2011); an elastic face sheet supported by metallic ribbons that can perform shear compression morphing has been utilized on an unmanned aerial vehicle of NextGen Aeronautics with capacity of $200 \%$ change in aspect ratio, $40 \%$ change in span, and $70 \%$ change in wing area (Bowman et al., 2007; Olympio, 2009); and a fishbone-like structure covered by elastic composite skin has been used as the rear part of airfoil that enables camber change (Woods and Friswell, 2012).

\footnotetext{
'School of Materials Science and Engineering, Harbin Institute of Technology, Harbin, P.R. China

${ }^{2}$ Centre for Composite Materials and Structures, Harbin Institute of Technology, Harbin, P.R. China

${ }^{3}$ School of Astronautics, Harbin Institute of Technology, Harbin, P.R. China
}

\section{Corresponding author:}

Jinsong Leng, P.O. Box 30I I, No. 2 YiKuang Street, Centre for

Composite Materials and Structures, Science Park of Harbin Institute of Technology (HIT), Harbin I50080, P.R. China.

Email: lengjs@hit.edu.cn 
This work has been performed as a part of the development of an innovative aircraft demonstrator with morphing wing, which involved the design of a morphing skin that can be simply manufactured. This skin should be able to perform pure shear deformation when driven by actuators mounted on the wing structure. A silicone rubber matrix composite skin reinforced by carbon fiber-reinforced plastic (CFRP) rods and Kevlar has been developed to meet the specifications of the design. The following paragraphs describe the overall process of design, fabrication, and testing of this composite skin.

\section{Skin design}

In this project, a satisfactory skin design should meet the following requirements:

1. Capability of performing pure shear deformation while maintaining the wing profile;

2. Low demand for the actuating force, which reduces the stress in the actuator and wing structure and therefore reduces the weight of aircraft;

3. Resistance to out-of-plane deformation under steady aerodynamic load;

4. Low surface density, which is the weight per unit skin area;

5. Simplicity of fabricating and mounting.

Two preexisting concepts are first considered. The unidirectional fiber-reinforced elastomer skin requires high pre-tension force on the fiber direction in order to achieve sufficient loading capacity (Murray et al., 2010), and this will result in heavy load on wing structure and may also require high creep resistance of fiber. The honeycomb substructure is advantageous for loadbearing characteristics; however, it would be sophisticated in design and fabrication when being required to fit on curved surface of wing.

\section{Unidirectional CFRP rod-reinforced skin}

With the consideration presented above, an anisotropic skin with a substructure-dominated direction on which the loading capacity is achieved and a matrixdominated direction with low bending modulus, which enables the skin to be bent to fit on curved surface, is preferred in this study. TC-5005 A/B-C silicone rubber supplied by BJB Enterprises has been selected as matrix material due to its flexible nature and designability in modulus.

A composite skin with CFRP rod reinforcement is considered, which consisted of silicone rubber matrix and evenly spaced CFRP rods along a single direction in the middle plane of matrix (Figure 1(a)). During fabrication process, the rods are set in position before the curing of matrix. This skin is capable of pure shear morphing or 1D morphing perpendicular to the rods (Figure 1(c)).

Several skins are fabricated and tests are carried out to let these skins perform the required shear morphing under different pre-stretch that is perpendicular to the rods. These skins are $2 \mathrm{~mm}$ in thickness with CFRP rods of $0.5-1.5 \mathrm{~mm}$ in diameter and $5-10 \mathrm{~mm}$ in spacing. During the tests, the skins are mounted on $100 \mathrm{~mm}$ $\times 100 \mathrm{~mm}$ square frames that can perform pure shear morphing of $50^{\circ}$, and the rods are parallel to a side of the frame.

The results of these tests reveal two major drawbacks of this skin design for pure shear morphing application:

1. The damage tolerance of the skins is low because when the skin is under load or prestretch, a crack in matrix caused by damage or defect such as a bubble may propagate along the rod-dominated direction which is normal to the direction of tensile stress, resulting in the failure of whole skin (Figure 1(b)).

2. Pre-stretch that is perpendicular to the rods should be applied in order to reduce wrinkles created in matrix under shear morphing. This often results in local debonding between rods and matrix (Figure 1(b)) and then weakens the strength of skin.

This skin configuration has achieved designability on some mechanical properties that will be discussed in section "Study on out-of-plane stiffness," as well as simplicity in fabricating and mounting, but still inapplicable in practice because of the problems mentioned above. A satisfactory design should realize enhanced reliability and wrinkle reduction strategies without prestretching.

\section{Unidirectional CFRP-rods- and Kevlar-reinforced skin}

In order to overcome the drawbacks mentioned in the last section, a serpentine bundle of Kevlar is applied into both surfaces of skin (Figure 2(a)), with the part of it cured into matrix at a depth of approximately 0.5 $\mathrm{mm}$, unidirectional and perpendicular to the rods. The ends form rings, which can be useful in fabricating and mounting.

Several skins are fabricated in the following method. First, three separated fixtures are manufactured. They are rectangular frames that can hold one layer of Kevlar or CFRP rods before the curing of matrix. The frames can be fit together to set different layers of Kevlar and CFRP rods in position. Then, silicone rubber is poured onto a glass surface covered by peel ply and enclosed by short walls with $2 \mathrm{~mm}$ height; the depth of rubber is controlled to approximately $1.5 \mathrm{~mm}$. Then, the fixture holding the Kevlar that should be set 0.5 $\mathrm{mm}$ above the peel ply (here a skin surface will form), 


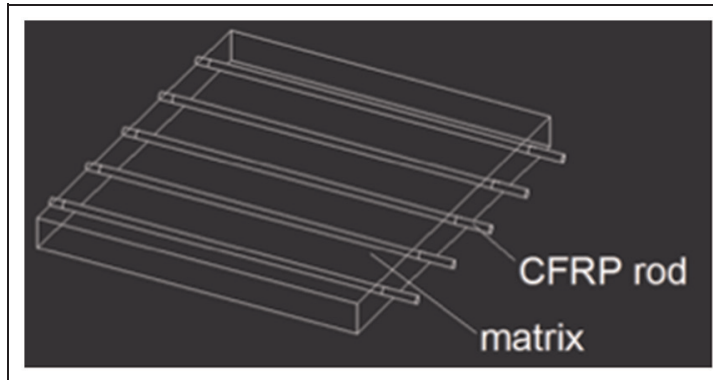

(a)

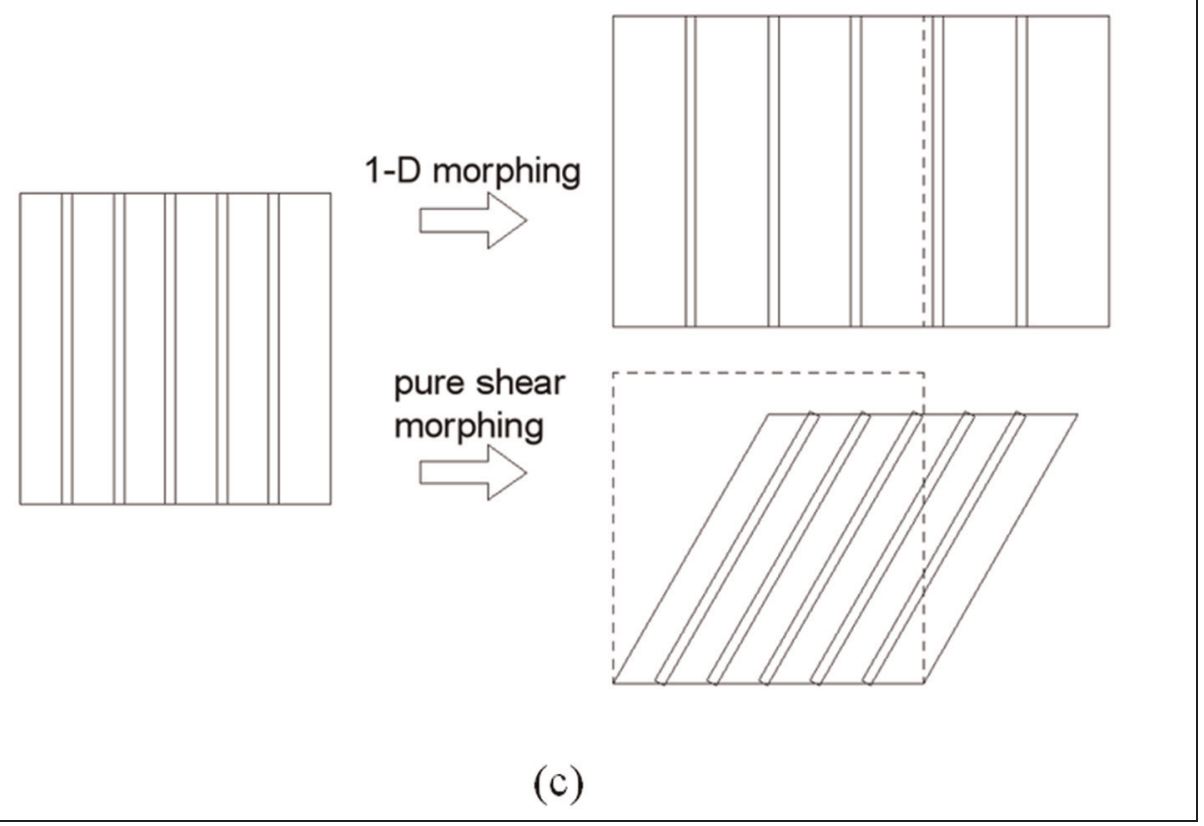

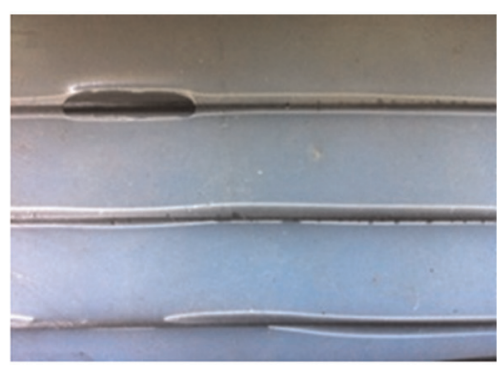

(b)

Figure I. Unidirectional CFRP rod-reinforced skin: (a) structural sketch, (b) rod/matrix boundary failure and propagated crack under lateral strain, and (c) ID morphing and pure shear morphing. CFRP: carbon fiber-reinforced plastic; ID: one-dimensional.

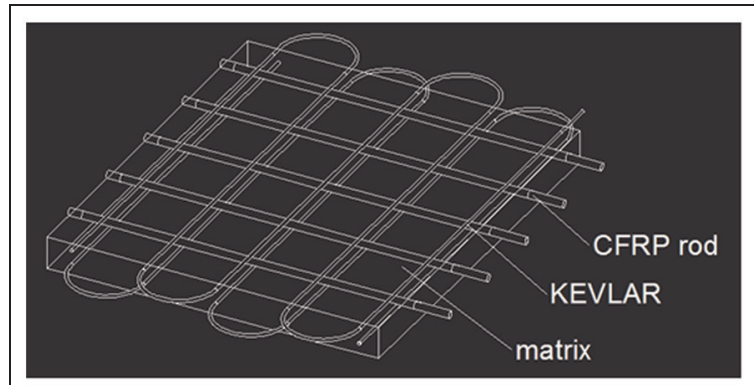

(a)

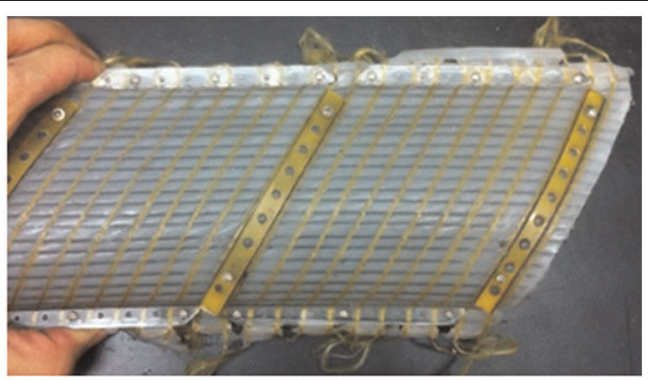

(b)

Figure 2. Unidirectional CFRP-rods- and Kevlar-reinforced skin: (a) structural sketch and (b) wrinkle reduced in a curved skin without pre-stretching.

CFRP: carbon fiber-reinforced plastic.

the fixture holding CFRP rods, and the fixture holding the other layer of Kevlar are applied in turn. After the rods and Kevlar are immersed into the silicone rubber, the depth of rubber is adjusted to maintain a thickness of $2 \mathrm{~mm}$. After curing in room temperature, a silicone rubber matrix composite with one layer of CFRP rod 
reinforcement between two layers of Kevlar reinforcement is formed and can be removed from the fixtures and glass surface easily.

To be noted, although fixtures are utilized, the rod spacing may still become uneven due to the initial deflection (manufacturing defect) of CFRP rods, and the alignment of Kevlar may be influenced by the flow of silicone rubber. This nonuniform distribution configuration of reinforcing structures may affect the wrinkle reduction performance.

The skins are tested in the similar way as mentioned in the last section, but pre-stretch is not applied. To be noted, this skin is not capable of $1 \mathrm{D}$ morphing due to the constraint of fiber, but the pure shear morphing is not constrained because the fiber is parallel to a side of the frame, along which no strain is induced.

The tests show that the damage tolerance of skin is significantly enhanced. This is because the CFRP rods and Kevlar constrain the tensile strain in nearby matrix that is, for example, induced by morphing or out-ofplane load, and then, the cracks in matrix would not propagate across the area near these structures. The cracks are trapped in the mesh formed by rods and fiber.

The tests also show that the wrinkle is reduced effectively without any pre-tension (Figure 2(b)). The research on wrinkle reduction of this skin will be discussed in the next section.

\section{Wrinkle reduction}

Wrinkling characteristics are of vital importance because skin must continuously form a smooth surface that is free of wrinkles in the whole process of shape morphing to maintain aerodynamic performance and efficiency of aircraft (Olympio et al., 2010; Potluri et al., 2010). Wrinkle reduction is especially important to the presented skin design because in comparison with honeycomb structure and corrugated structure, where the maximum local stress induced by morphing might be the most significant morphing barrier, the stress in the presented skin induced by morphing is considerably lower since it is based on soft matrix material, and onset angle of wrinkles, instead of maximum local stress, should be the most significant barrier that determines the maximum morphing angle.

A wrinkle reduction strategy with no requirements on pre-tension and pre-stretching, which is achieved by applying unidirectional stiff fiber and rigid rods, is proposed and proved to be effective by experiments. The following describes the analysis and characterization of wrinkles as well as the design and testing of the structure for wrinkle reduction.

\section{Analysis of wrinkling behavior}

Wrinkles of skin are formed when the matrix buckles under compressive normal stress. Structures that enhance the stability of matrix, therefore, would help increase the critical strain under which the wrinkles begin to develop and then reduce wrinkles.

In case of the presented CFRP rod-reinforced skin, two types of wrinkle patterns may occur. The pattern of first-type wrinkles developed during pure shear morphing is shown in Figure 3(a), which is caused by buckling of the skin strip between adjacent rods under compressive principal strain. The cross section of the same morphed skin along A-A' (the direction of compressive principal strain is shown in Figure 3(a)) and perpendicular to skin surface is shown in Figure 4(a). To be noted, the rods are not deflected when first-type wrinkles appear, and the matrix near rods remains flat. This type of wrinkles, therefore, actually happens in identical matrix regions separated by rods. The pattern of second-type wrinkles is shown in Figure 3(b), which is generated only along matrix-dominated direction, in which the skin presents the lowest stability since the rod reinforcement is least effective in this direction. In this occasion, rods are deflected to produce second-type wrinkles.

The first-type wrinkles can be reduced effectively by decreasing the slenderness ratio of the cross section of skin strip between adjacent rods along $\mathrm{A}-\mathrm{A}^{\prime}$ (which is the ratio between the length of $\mathrm{A}-\mathrm{A}^{\prime}$ and skin thickness) since the decreased slenderness ratio leads to increased stability. Discretion of the slenderness ratio can be achieved through two methods: increasing the thickness of skin or decreasing the space between rods. The possible cross sections of revised skins along $\mathrm{A}-\mathrm{A}^{\prime}$ are shown in Figure 4(b).

According to the expression of skin's out-of-plane deflection under load, which will be presented by equation (2) in section "Theoretical analysis," when keeping the skin's out-of-plane stiffness constant, reduced rod spacing (which results in increased number of rods) leads to smaller rod radius, and the slenderness ratio mentioned in the last paragraph also decreases as it is shown by equation (1)

$$
i=\frac{s}{\left(L \cdot \sqrt[4]{\frac{5 s P}{6 \pi E \delta}}+\Delta\right)}
$$

where $i$ is the slenderness ratio, $\Delta$ is the difference between rods' diameter and skin's thickness, $\delta$ is the deflection on center point of skin, $s$ is the spacing between adjacent rods, $P$ is the evenly distributed pressure on skin, $L$ is the length of skin along rods' direction, $E$ is the modulus of CFRP along the fiber direction, and $d$ is the diameter of rods.

Therefore, the thickness of skin is related to the space between rods. In order to reduce weight and actuating work, the thickness of skin should be reduced toward the minimum. Tentatively, the thickness is set to be slightly thicker (e.g. set $\Delta=1 \mathrm{~mm}$, which is 0.5 


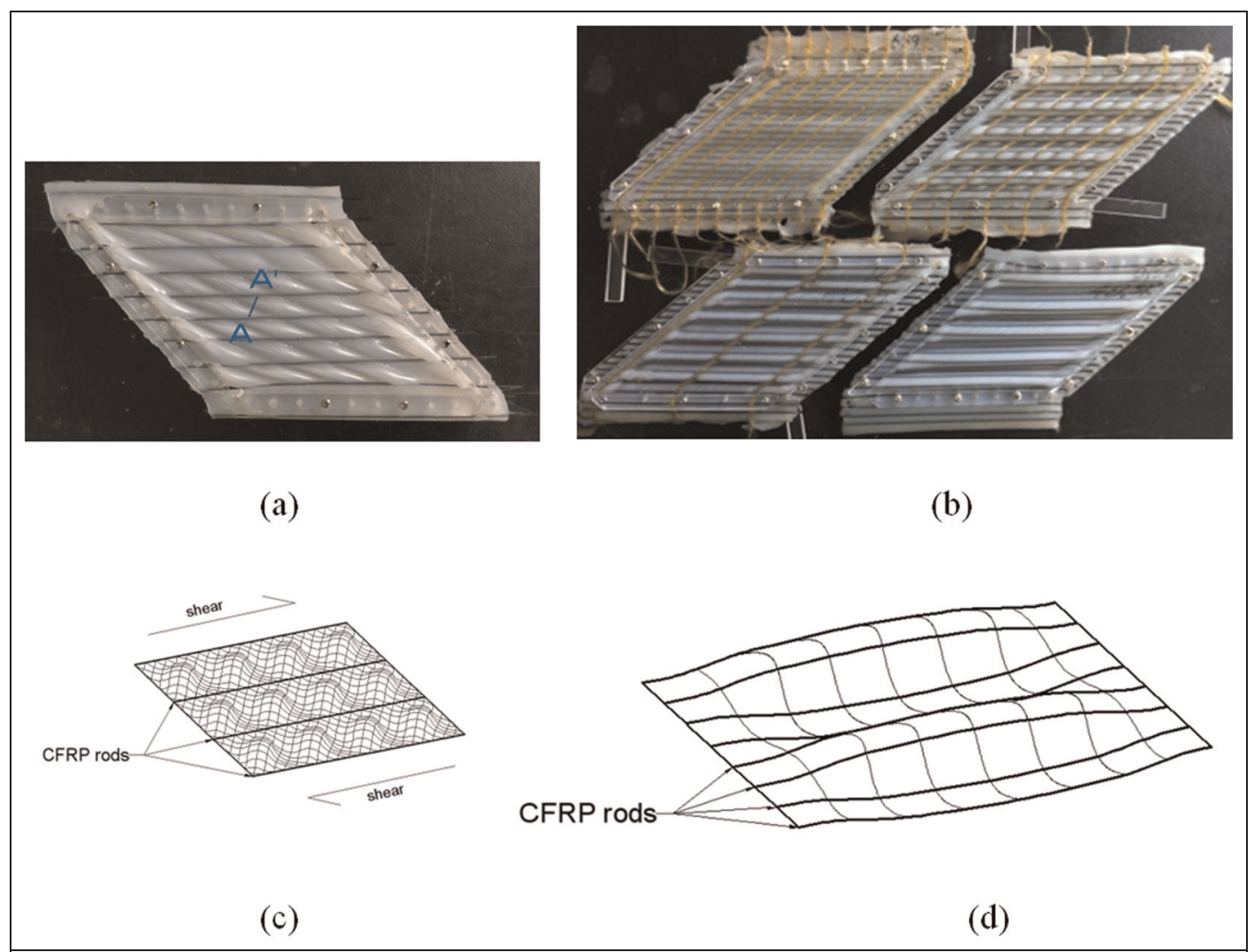

Figure 3. Patterns of different types of wrinkles: (a) first-type wrinkles developed in unidirectional CFRP rod-reinforced skin, (b) comparison between second-type wrinkles developed in unidirectional CFRP rod-reinforced skin (bottom right) and the ones with different Kevlar fiber reinforcements, (c) general pattern of first-type wrinkles, and (d) general pattern of second-type wrinkles. CFRP: carbon fiber-reinforced plastic.

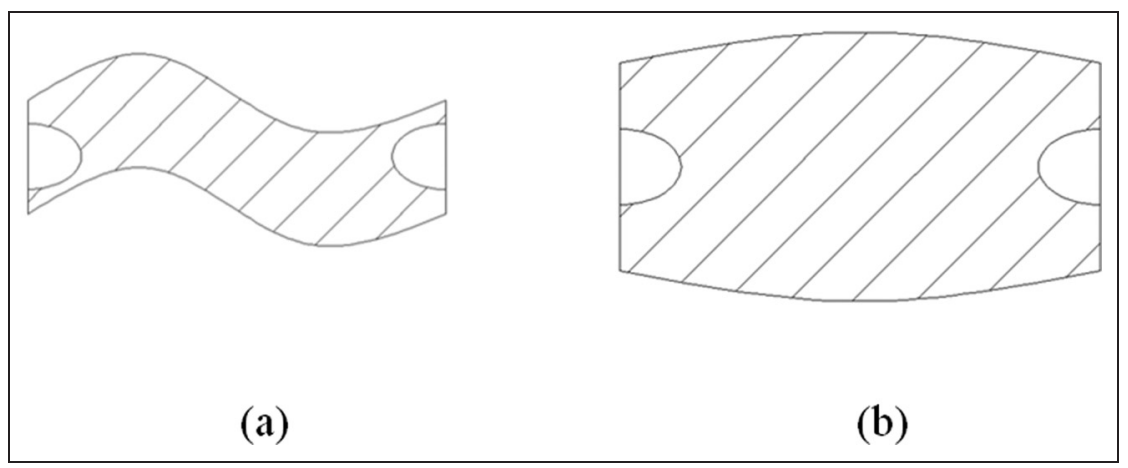

Figure 4. Reduction of first-type wrinkle achieved by enhancing the stability of skin strip between adjacent rods: (a) cross section along $A-A^{\prime}$ and (b) same cross section of an enhanced skin.

$\mathrm{mm}$ on each side) than the diameter of rods since it is approximately the minimum thickness of skin that can be manufactured.

According to the discussion presented above, reducing rod spacing is favorable for achieving not only weight reduction and low actuating work but also better wrinkle reduction performance on first-type wrinkles. However, increased rod number can complicate the manufacturing process and cause other problems. The rod diameter in this study is set, based on the demand of demonstrating aircraft, to $1 \mathrm{~mm}$ with $5 \mathrm{~mm}$ spacing. The skin thickness is then set to $2 \mathrm{~mm}$.

In order to alleviate second-type wrinkles effectively, the stability of the whole skin along the direction perpendicular to rods should be enhanced. In this case, the increase in the skin thickness is not a viable option. Increased thickness leads to smaller thickness slenderness ratio (i.e. ratio between thickness and the span along the matrix-dominated direction) and consequently higher stability. However, since the thickness is 


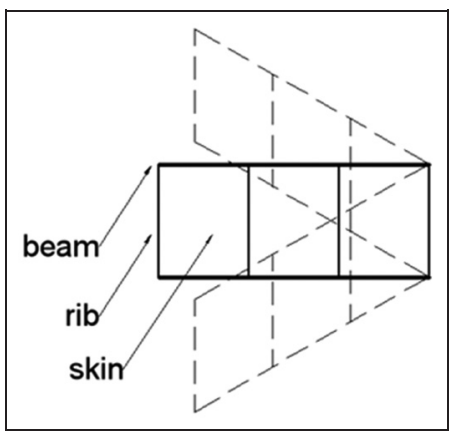

Figure 5. Morphing process of a part of wing panel as supporting structure of skin (the solid line represents the configuration in mid-stroke where ribs are perpendicular to beams, while the dashed line represents the stroke ends).

limited by other constraints such as allowable actuation work and weight, the slenderness ratio cannot be sufficiently small to have considerable effect on the reduction of the second-type wrinkle. Considering that during the formation of second-type wrinkles the skin undergoes bending and elongation, stiff fiber is applied on both surfaces of skin and in a unidirectional pattern perpendicular to the rods to constrain such deformation.

To keep the actuating force requirement to the minimum, the skin should be designed to be undeformed (free of stress) in the mid-stroke of morphing. In the demonstrator aircraft, the skin is mounted on ribs and beams that are perpendicular to each other in the midstroke, as shown in Figure 5. Therefore, the direction of fiber (which is along the ribs) is set to be perpendicular to the rods (which are along the beams). In fact, this design has a drawback in wrinkle reduction: the rod spacing will be reduced by shear morphing and then results in compressive normal stress. This problem can be overcome by setting the skin undeformed on a stroke end, but this may increase the maximum shear strain during the morphing stroke and cause problem in actuating work. However, the compressive normal stress favors the safety of skin because cracks or partial debondings in matrix cannot propagate in this condition.

\section{Characterization of wrinkles}

In order to measure the wrinkle reduction performance of skins and make comparisons between different skin designs in practice, two characterization methods for wrinkles are brought out in this section.

Wrinkles can be measured by comparing the tested load-deformation curve of real skin that wrinkles under pure shear morphing with ideal curve of unbuckled skin without wrinkles. Because buckling is a representation of the lowest energy principal that leads to reduction of stress caused by morphing, the buckling of skin that indicates the beginning of wrinkling, therefore, can be spotted on the curves by looking for the point from which the curve deviates from ideal curve or starts to decline abruptly. This method is effective on spotting the onset angle of wrinkles represented by the strain value of the deviating point, as well as the degree of wrinkle represented by the deviation from ideal curve.

Another characterization method is to visually observe a skin that is illuminated on one side from an aspect perpendicular to skin surface on the other side. When the skin is flat and with no wrinkles in it, light will transmit straightly through the skin and form a uniformly illuminated view, whereas when the skin wrinkles, the transmission light will undergo deflection and cause a lateral displacement of emergent light (Figure 6(a)), and then, wrinkles can be spotted by looking for dark regions in the view. The typical patterns of first- and second-type wrinkles are presented in Figure 6(b) and (c). To be noted, first-type wrinkles are always forming simultaneously with second-type wrinkles because the formation of second-type wrinkles will cause extra compressional normal stress in the concave parts of skin.

During the tests, the skins are mounted on a similar device with the same dimensions as the one mentioned in section "Unidirectional CFRP rod-reinforced skin," but two handles are added on the hinge pivots on opposite corners, which can be used when clamped by tensile machine. The tests are carried out on a tensile machine (Zwick/Roell Z010) with $500 \mathrm{~N}$ load cell at $2 \mathrm{~mm} / \mathrm{s}$ crosshead speed, and the crosshead displacement is used to plot the curves. Meanwhile, visual observation is applied using a light-emitting diode (LED) as illuminant and a fixed camera controlled by software that starts video recording simultaneously with the start of tensile machine. The resolution of video is $320 \times 240$, and the frame rate is 25 . The equipment used in the tests excluding the LED is shown in Figure 7(a). A sample from a video record is shown in Figure 7(b).

\section{Parameter study on wrinkle reduction strategy}

The impact of fiber configuration on wrinkle reduction effect is studied through the tests on a series of skins with the thickness of $2 \mathrm{~mm}$ and various fiber configurations. The variable parameters are as follows: fiber spacing and relative location of the fiber in both surfaces, that is, overlapped and staggered. Overlapped means the fibers on both sides of skin are on the same location along the rods, as shown in Figure 8(a). Staggered means the fibers on different sides are evenly staggered, as shown in Figure 8(b). To be noted, the fiber spacing is the space between fibers regardless of different sides of skin, for example, if the fibers on both sides are $10 \mathrm{~mm}$ in spacing and the fibers are staggered, then fiber spacing is $5 \mathrm{~mm}$. 


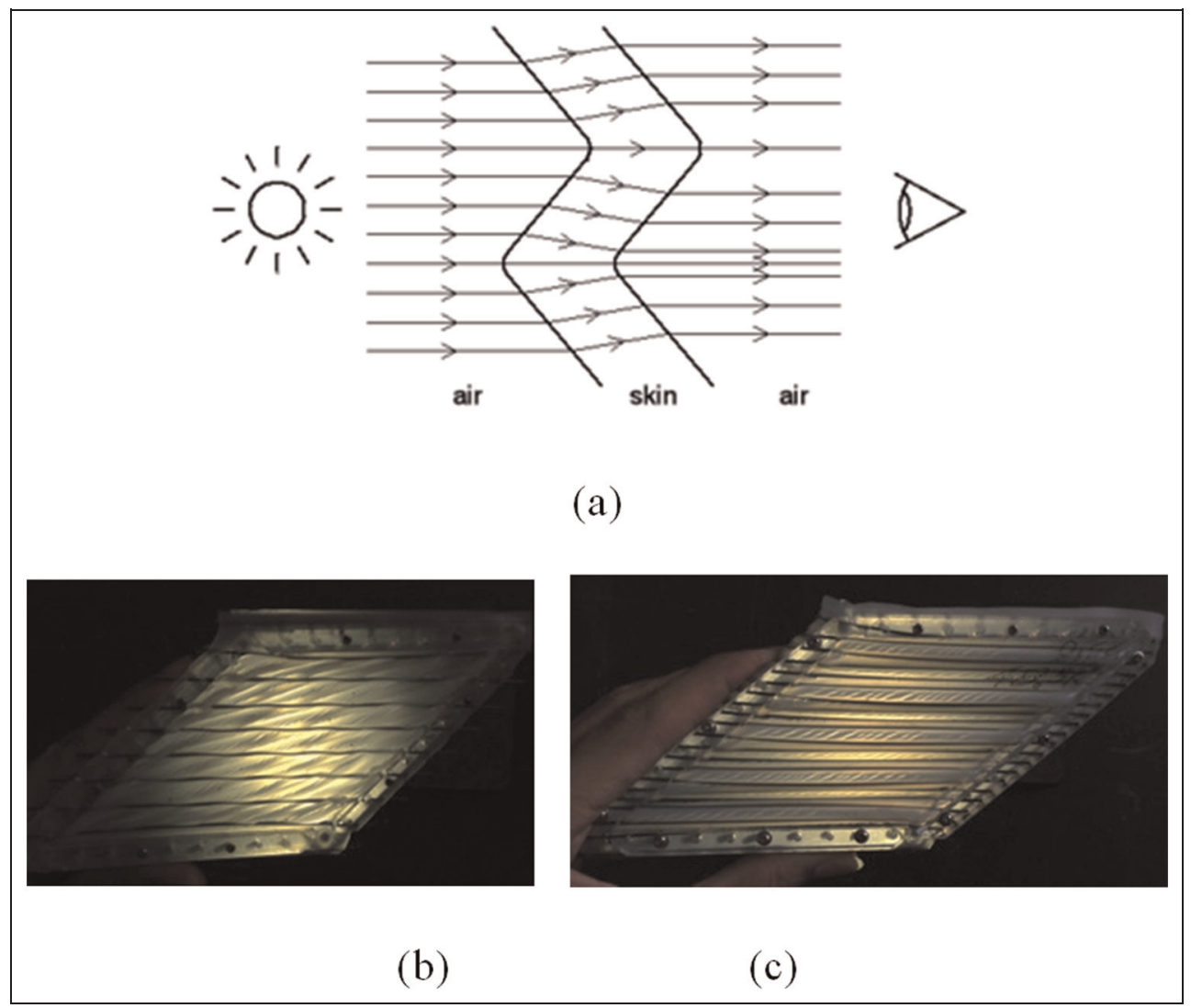

Figure 6. Visual observation of a unilaterally illuminated skin: (a) qualitative analysis, (b) typical first-type wrinkles, and (c) typical second-type wrinkles with first-type wrinkles generated simultaneously.

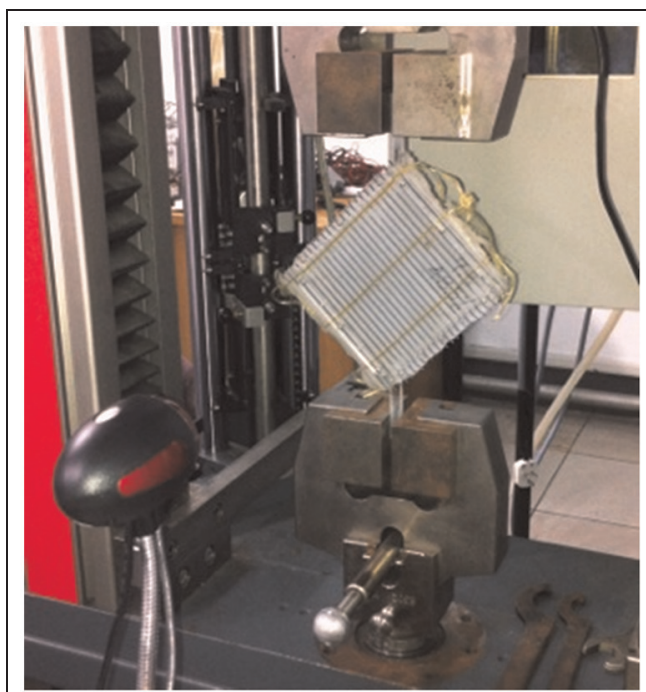

(a)

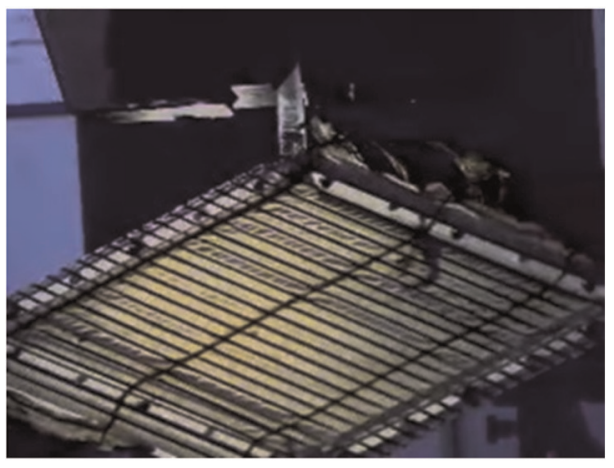

(b)

Figure 7. Testing on load-deformation curve: (a) equipment used excluding the LED and (b) a sample of the video records of skin at an onset angle of wrinkles.

The information on the tested skins and the corresponding onset angles of wrinkles are listed in Table 1.

Four typical "load-deformation" curves obtained from four different skins are shown in Figure 9.
The approximate wrinkle onset points are also marked on the curves. To be noted, the value of load is incomparable between different skins since the modulus of matrix fabricated separately can be different due to 


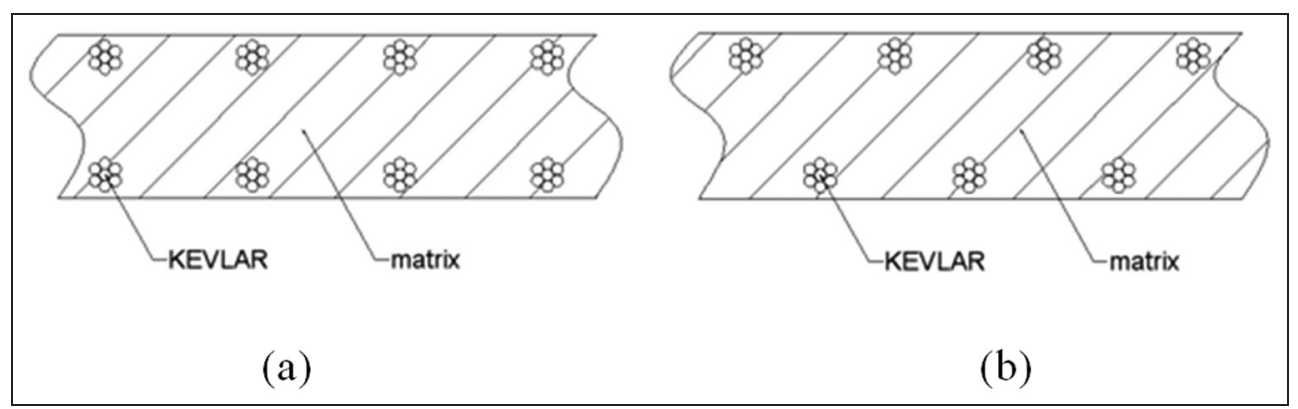

Figure 8. Different types of fiber relative location: (a) overlapped and (b) staggered.

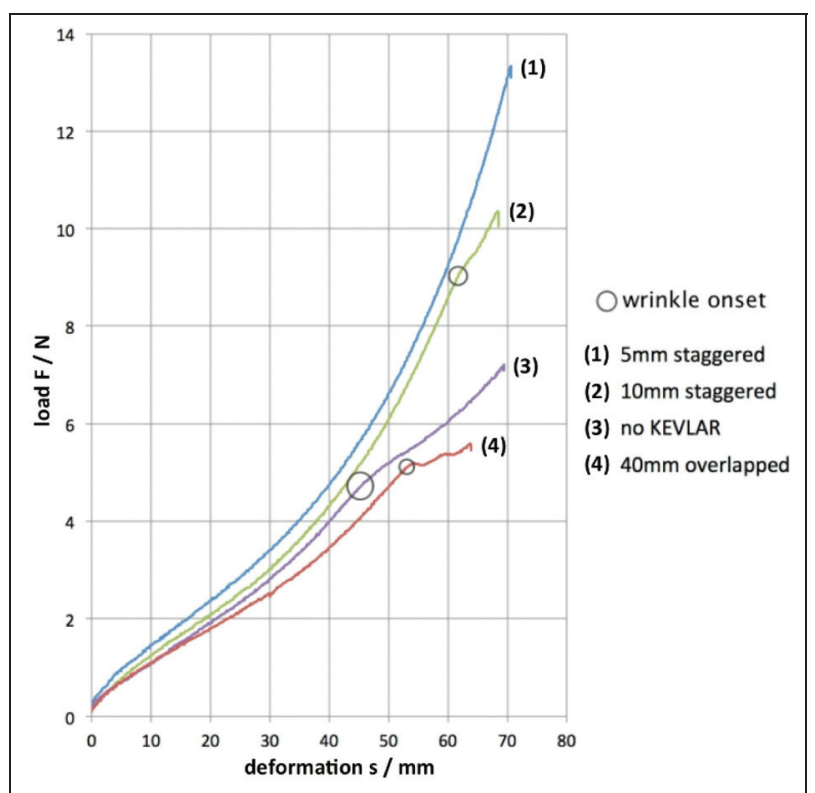

Figure 9. Typical "load-deformation" curves with wrinkle onset points marked.

deviation in silicone rubber formulation and curing condition.

From the results in Table 1, we may infer that fiber spacing is the dominating factor for the skin's wrinkle onset angles when it is large, while fiber relative location dominates when fiber spacing is low.
It can be seen from Table 1 that in some cases, there are more than one onset angles. This is because the tested skins are not absolutely uniform, and the onset angles in different areas will be slightly different. The first wrinkle, therefore, will be generated in the area with lowest onset angle, as it is shown in Figure 7(b), and the formation of next wrinkle will be delayed to the next onset angle since the stress in matrix has been relieved due to the first wrinkle.

It can also be seen that the first onset angles spotted on curves are lower than those spotted on videos. All the corresponding wrinkles in these tests are formed in a relatively short period of time and concentrated in single skin strips between adjacent rods. To be noted, during the tests on skin with overlapped fiber reinforcement of $10 \mathrm{~mm}$ spacing, some signs of wrinkles have been ignored during visual observation when the corresponding wrinkles are formed locally and not in adjacent meshes due to local defects. These wrinkles barely influence the total load and are invisible on the curve, but still affect the performance of skin. We may infer that the "load-deformation" curve is an effective way for detecting major wrinkles in uniform skin and the visual observation is suitable for detecting local wrinkles.

\section{Study on out-of-plane stiffness}

Out-of-plane stiffness influences the load-bearing capacity of skin and is significant to the aerodynamic

Table I. Testing results on wrinkle onset angles.

\begin{tabular}{llll}
\hline Fiber spacing $(\mathrm{mm})$ & Fiber relative location & Onset angle spotted on curve & Onset angle spotted visually $\pm 0.2^{\circ}$ \\
\hline 5 & Staggered & N/A & N/A \\
10 & Overlapped & N/A & N/A \\
20 & Overlapped & $44.9^{\circ}$ & $45.3^{\circ}$ \\
10 & Staggered & $41.3^{\circ}$ & $41.9^{\circ}$ \\
20 & Staggered & $41.6^{\circ}$ & $42.1^{\circ}, 47.0^{\circ}, 50.0^{\circ}$ \\
40 & Overlapped & $36.4^{\circ}$ & $37.0^{\circ}, 39.5^{\circ}, 42.0^{\circ}$ \\
$\infty$ & N/A & $31.4^{\circ}$ & $35.7^{\circ}$ \\
\hline
\end{tabular}

N/A: not available. 


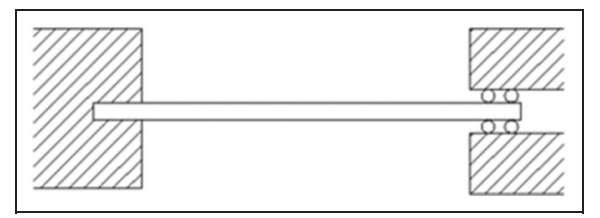

Figure 10. Mechanical model of CFRP rod in the skin: fixed end beam.

Table 2. Details of the skins used in out-of-plane stiffness test.

\begin{tabular}{lll}
\hline $\begin{array}{l}\text { Diameter of } \\
\text { rods }(\mathrm{mm})\end{array}$ & $\begin{array}{l}\text { Spacing of } \\
\text { rods }(\mathrm{mm})\end{array}$ & Notes \\
\hline 2 & 5 & \\
1.5 & 5 & \\
1 & 2.5 & \\
1 & 4 & With fiber \\
1 & 5 & reinforcement \\
1 & 5 & \\
1 & 6 & \\
1 & 7.5 & \\
0.8 & 5 & \\
\hline
\end{tabular}

performance of wing. Therefore, achieving sufficient out-of-plane stiffness is critical to morphing skin design.

\section{Theoretical analysis}

In case of the presented CFRP-rods- and Kevlar-reinforced skin, the effect of Kevlar to out-of-plane stiffness of skin can be ignored since there is no pre-tension in it; the effect of matrix can also be ignored (Murray et al., 2010). Therefore, neglecting the effect of skin aspect ratio, we assume that the out-of-plane stiffness of such skin is only related to the characteristics and configuration of CFRP rods that can be modeled as a series of identical fixed end beams with uniform circular cross section under small deflection (Figure 10). Then, from mechanical analysis of linear elastic beam, we get the expression of the skin's out-of-plane deflection under evenly distributed load (Gere and Goodno, n.d.)

$$
\delta=\frac{5 s P L^{4}}{6 \pi E d^{4}}
$$

where $\delta$ is the deflection on center point of skin, $s$ is the spacing between adjacent rods, $P$ is the evenly distributed pressure on skin, $L$ is the length of skin along rods' direction, $E$ is the modulus of CFRP along the fiber direction, and $d$ is the diameter of rods.

\section{Out-of-plane deflection test}

Tests are also carried out to measure the out-of-plane stiffness of a series of skins with same thickness of 2

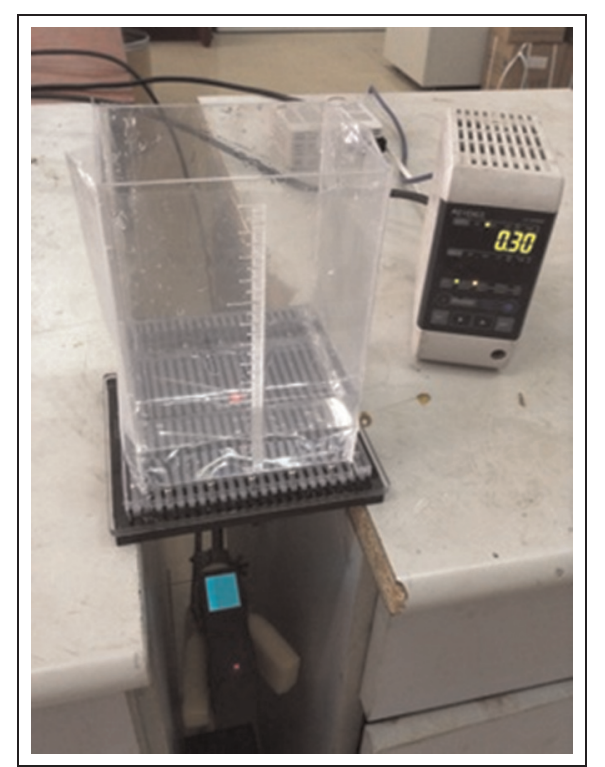

Figure I I. Devices used in out-of-plane deflection testing.

$\mathrm{mm}$ but different detail designs. The details of these skins are presented in Table 2.

The testing device is shown in Figure 11. A rigid frame with the span of $82 \mathrm{~mm}$ (to simulate the condition of skin on demonstrator aircraft) and a cord of $100 \mathrm{~mm}$ is used to mount tested skins. CFRP tubes are added onto the frame to minimize its deflection under load. The loading material is water in plastic bag. The plastic bag also envelopes enclosing walls with scale. A laser displacement sensor is set beneath the skin to measure the out-of-plane displacement of the points on skin's lower surface with the tolerance of $0.01 \mathrm{~mm}$. The measured points are set both beneath the rods (which will be called the rod's deflection) and beneath the midpoint between adjacent rods and Kevlar (which will be called matrix's deflection). During the tests, water is poured into the enclosing walls that are put onto the skin, and the depth of water is adjusted according to the scale on the wall to control the applied pressure. The enclosing walls are $150 \mathrm{~mm}$ in height; the maximum pressure that can be achieved with this device, therefore, is $1.47 \mathrm{kPa}$, which is the maximum absolute value of pressure on elastic skin of the demonstrator aircraft under velocity of approximately 0.115 Mach.

To validate equation (2), equation (3) shown below is fitted to the resulted data on the rod's deflections of skins and rods' diameters

$$
\delta=A \cdot d^{-4}+b
$$

The parameter $A$ is related to $s, P, L$, and $E$ in equation (2). The fitted values of $A$ show a linear relationship with $P$, which is expected by equation (2). The parameter $b$ is set in the function to compensate the extra deflection caused by testing devices such as the frame or the test bench, which is also measured by experiment. 


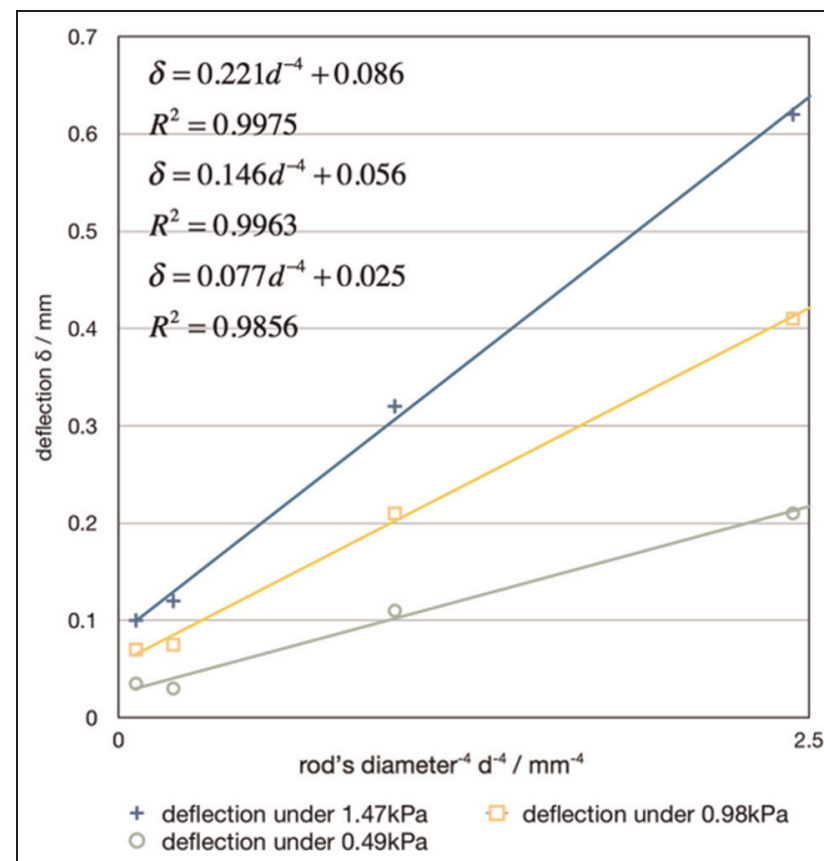

(a)

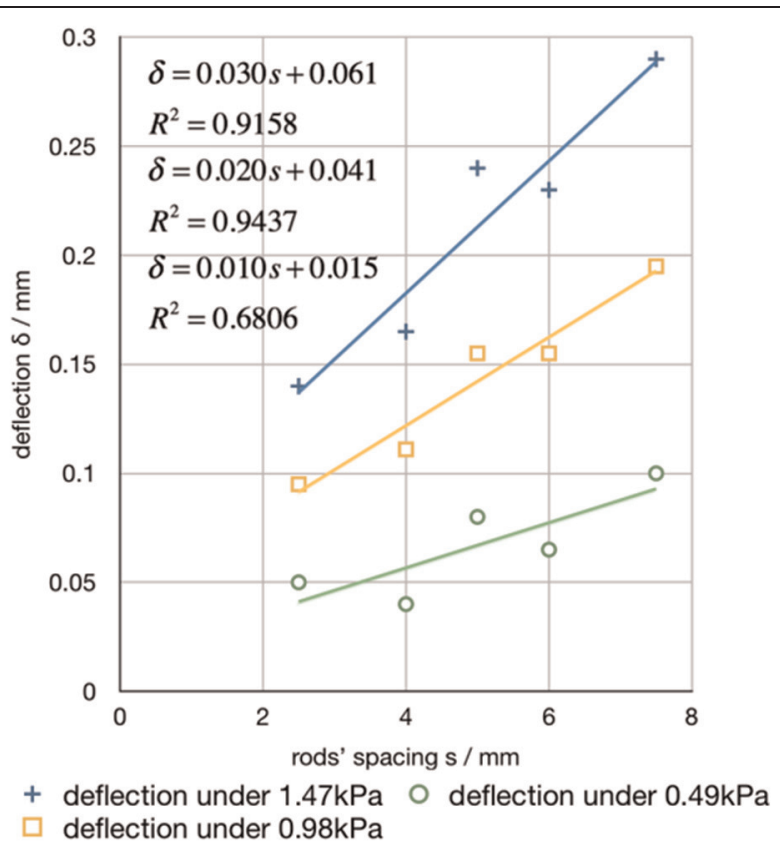

(b)

Figure 12. Testing results of rod's deflection: (a) relationship between rods' diameter and rod's deflection (with constant spacing of $5 \mathrm{~mm}$ ) and (b) relationship between rods' pacing and rod's deflection (with constant diameter of I mm).

The fitted values of $b$ match the experimental results with a satisfactory tolerance of $\pm 0.006 \mathrm{~mm}$. The fitted values of $\delta$ are plotted against $d^{-4}$ (Figure 12(a)), which show linear relation as predicted by equation (2). In conclusion, the relationship between rods' diameter and rod's deflection matches the prediction of equation (2) well.

The testing results on the relationship between rods' spacing and rod's deflection, which have been modified by subtracting the extra deflection of testing devices according to the values of parameter $\mathbf{b}$, are shown in Figure 12(b). The linear fitting functions show that this relationship generally matches the prediction of equation (2).

To be noted, the discussions above are focused on the deflection of the rod. In fact, the matrix's deflection is of greater concern since it is larger. The tests show that the increment of matrix's deflection in comparison with rod's deflection is probably related to rods' spacing and rods' diameter and makes up around 10\%$50 \%$ of the total deflection.

The tests also show that the presence of Kevlar without pre-tension barely influences the out-of-plane stiffness of the skin.

\section{Utilization of skin on demonstrator wing}

A demonstrator aircraft on which the composite skin proposed above is utilized has been manufactured and tested on ground. The structure of a half wing without skin is shown in Figure 13(a), which consisted of two wing panels that are hinged together and can morph independently. Each wing panel is based on a parallelogram morphing frame consisted of two beams and ribs that are hinged onto the beams, and the wingboxes are fixed onto the beams. Shear morphing is established by changing the angle between beam and rib while the wingboxes remain undeformed. Hydraulic cylinders are utilized as morphing actuators. Morphing skin will be mounted onto the top and the bottom of ribs and beams to form continuous surfaces between wingboxes.

The bending stiffness of the wing is mostly provided by the beam, while the torsional stiffness is mostly provided by wingboxes, and the function of morphing skin is to keep the aerodynamic surface continuous and transmit aerodynamic load. A manufactured wing panel is shown in Figure 13(b).

The skin can be easily mounted on supporting structure by applying normal pressing force since there is no required pre-tension or pre-stretch of skin. The pressing force can be applied using strips (the black strips in Figure 13(b)) that are fixed to the beams or ribs and clamp the skin in between. During the morphing test on ground, no wrinkles are observed (Figure 13(b)).

\section{Conclusion}

This study is motivated by the demand for a morphing skin with capacity of $\pm 30^{\circ}$ pure shear morphing for a 


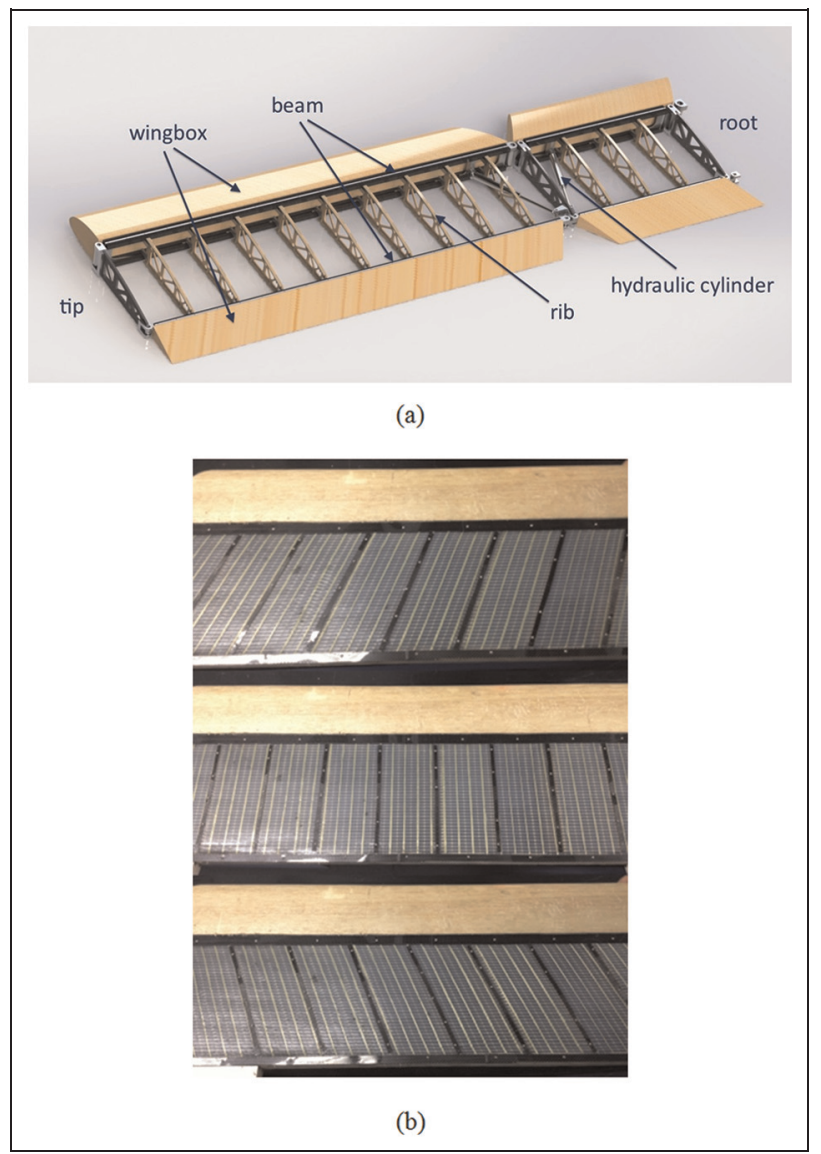

Figure 13. The demonstrator morphing wing: (a) wing structure excluding morphing skin and (b) morphing process of a wing panel during ground test.

morphing wing demonstrator aircraft. Focused on the practical concerns, a design of composite skin that can be easily manufactured with silicone rubber matrix and CFRP rods as well as Kevlar reinforcements is brought up.

1. An effective structure for wrinkle reduction consisted of CFRP rods and Kevlar is investigated. With such structure, unstretched skins with 2 $\mathrm{mm}$ thickness and no pre-tension in any structure can be free of wrinkles under shear morphing larger than $45^{\circ}$. The absence of stretch and pre-tension can enhance safety, reduce the load on supporting structure, simplify the mounting process, and increase the tolerance on creep.

2. In order to detect the wrinkles and therefore measure the onset angle of wrinkles, two methods including load-deformation curve testing and visual observation of a unilaterally illuminated skin are utilized. They are proved to be complementary to each other.

3. A series of out-of-plane stiffness tests has proved that the skin can be designed to have a certain out-of-plane stiffness by setting CFRP rods' diameter and spacing.

4. The skin is utilized on a demonstrator morphing wing, and the requirements on damage tolerance, mounting simplicity, wrinkle reduction, and loading capacity are met.

However, the practical applicability of this skin design still remains to be investigated because the performance such as weight and flutter speed are still questionable, and the loading capacity needs to be enhanced. Other critical issues such as degradation of elastomer caused by ultraviolet (UV) and ozone as well as cyclical fatigue should also be concerned in the future.

\section{Declaration of conflicting interests}

The authors declared no potential conflicts of interest with respect to the research, authorship, and/or publication of this article.

\section{Funding}

This work was supported by the National Natural Science Foundation of China (grant nos 11225211 and 11272106).

\section{References}

Airoldi A, Crespi M, Quaranta G, et al. (2012) Design of a morphing airfoil with composite chiral structure. Journal of Aircraft 49(4): 1008-1019.

Barbarino S, Bilgen O, Ajaj RM, et al. (2011) A review of morphing aircraft. Journal of Intelligent Material Systems and Structures 22(9): 823-877.

Bowman J, Sanders B, Cannon B, et al. (2007) Development of next generation morphing aircraft structures. In: Proceedings of 48th AIAA/ASME/ASCE/AHS/ASC structures, structural dynamics, and materials conference, Honolulu, HI, 23-26 April.

Bubert EA, Woods BKS, Lee K, et al. (2010) Design and fabrication of a passive 1D morphing aircraft skin. Journal of Intelligent Material Systems and Structures 21(17): 1699-1717.

Chen YJ, Scarpa F, Farrow IR, et al. (2013) Composite flexible skin with large negative Poisson's ratio range: numerical and experimental analysis. Smart Materials and Structures 22(4): 045005.

Chen YJ, Scarpa F, Remillat C, et al. (2013) Curved Kirigami SILICOMB cellular structures with zero Poisson's ratio for large deformations and morphing. Journal of Intelligent Material Systems and Structures. Epub ahead of print 3 September. DOI: 10.1177/1045389X13502852.

Dayyani I, Ziaei-Rad S and Friswell MI (2013) The mechanical behavior of composite corrugated core coated with elastomer for morphing skins. Journal of Composite Materials. Epub ahead of print 3 June. DOI: 10.1177/ 0021998313488807.

Gere JM and Goodno BJ (n.d.) Mechanics of Materials. Cengage Learning, Andover, UK. 
Joo JJ, Reich GW and Westfall JT (2009) Flexible skin development for morphing aircraft applications via topology optimization. Journal of Intelligent Material Systems and Structures 20(16): 1969-1985.

Love M, Zink P, Stroud R, et al. (2007) Demonstration of morphing technology through ground and wind tunnel tests. In: Proceedings of the 48th AIAA/ASME/ASCE/ AHS/ASC structures, structural dynamics, and materials conference, Honolulu, HI, 23-26 April.

Murray G, Gandhi F and Bakis C (2010) Flexible matrix composite skins for one-dimensional wing morphing. Journal of Intelligent Material Systems and Structures 21(17): 1771-1781.

Murugan S, Flores EIS, Adhikari S, et al. (2012) Optimal design of variable fiber spacing composites for morphing aircraft skins. Composite Structures 94(5): 1626-1633.

Olympio KR (2009) Compliant load-bearing skins and structures for morphing aircraft applications. PhD Thesis, The Pennsylvania State University, USA.

Olympio KR and Gandhi F (2007) Zero-v cellular honeycomb flexible skins for one-dimensional wing morphing. In: Proceedings of the 48th AIAA/ASME/ASCE/AHS/ $A S C$ structures, structural dynamics, and materials conference, Honolulu, HI, 23-26 April.

Olympio KR and Gandhi F (2010) Flexible skins for morphing aircraft using cellular honeycomb cores. Journal of Intelligent Material Systems and Structures 21(17): $1719-1735$.

Olympio KR, Gandhi F, Asheghian L, et al. (2010) Design of a flexible skin for a shear morphing wing. Journal of Intelligent Material Systems and Structures 21(17): 1755-1770.

Potluri VP, Nawaz S, Arshad H, et al. (2010) Development of novel skin materials for morphing aircraft. Report, University of Manchester, Manchester, November.
Rodriguez AR (2007) Morphing aircraft technology survey. In: Proceedings of 45th AIAA aerospace sciences meeting and exhibit, Reno, NV, 8-11 January.

Scarpa F and Tomlin PJ (2000) On the transverse shear modulus of negative Poisson's ratio honeycomb structures. Fatigue \& Fracture of Engineering Materials \& Structures 23(8): 717-720.

Thill C, Etches J, Bond I, et al. (2008) Morphing skins. Aeronautical Journal 112(1129): 117-139.

Thill C, Etches JA, Bond IP, et al. (2010) Composite corrugated structures for morphing wing skin applications. Smart Materials and Structures 19(12): 124009.

Vos R and Barrett R (2010) Pressure adaptive honeycomb: a new adaptive structure for aerospace applications. In: Proceedings of SPIE - the International Society for Optical Engineering, Smart Structures and Materials 2010Sensors and Smart Structures Technologies for Civil, Mechanical, and Aerospace Systems, vol. 7647, paper no. 76472B, San Diego, California, USA, 7-11 March, doi: $10.1117 / 12.847031$

Vos R and Barrett R (2011) Mechanics of pressure-adaptive honeycomb and its application to wing morphing. Smart Materials and Structures 20(9): 094010.

Woods BKS and Friswell MI (2012) Preliminary investigation of a fishbone active camber concept. In: Proceedings of the ASME 2012 conference on smart materials, adaptive structure and intelligent systems, Stone Mountain, GA, 19-21 September, pp. 1-9. New York: ASME.

Yokozeki T, Takeda S-I, Ogasawara T, et al. (2006) Mechanical properties of corrugated composites for candidate materials of flexible wing structures. Composites Part A: Applied Science and Manufacturing 37(10): 1578-1586. 